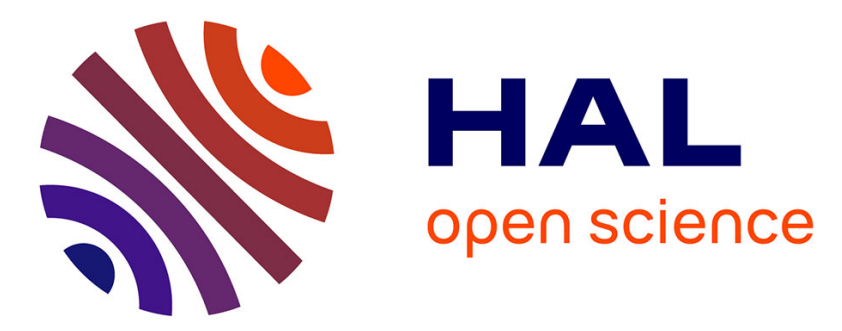

\title{
The fast and the curious II: performance, personality, and metabolism in Karoo bush rats
}

Paul Agnani, Jennifer Thomson, Carsten Schradin, Vincent Careau

\section{To cite this version:}

Paul Agnani, Jennifer Thomson, Carsten Schradin, Vincent Careau. The fast and the curious II: performance, personality, and metabolism in Karoo bush rats. Behavioral Ecology and Sociobiology, 2020, 74 (10), 10.1007/s00265-020-02908-y . hal-02966807

\section{HAL Id: hal-02966807 https://hal.science/hal-02966807}

Submitted on 14 Oct 2020

HAL is a multi-disciplinary open access archive for the deposit and dissemination of scientific research documents, whether they are published or not. The documents may come from teaching and research institutions in France or abroad, or from public or private research centers.
L'archive ouverte pluridisciplinaire HAL, est destinée au dépôt et à la diffusion de documents scientifiques de niveau recherche, publiés ou non, émanant des établissements d'enseignement et de recherche français ou étrangers, des laboratoires publics ou privés. 
1

2

3

4

5

6

7

8

9

10

11

20

21

22

23

24

25

26

27

28

29

30

\title{
The fast and the curious II:
} performance, personality and metabolism in Karoo bush rats

\author{
Paul Agnani ${ }^{1 *}$, Jennifer Thomson ${ }^{2}$, Carsten Schradin ${ }^{3,4}$, and Vincent Careau ${ }^{1}$
}

Published as

Agnani, P., Thomson, J., Schradin, C. \& Careau, V. 2020. The fast and the curious Il: performance, personality, and metabolism in Karoo bush rats. Behavioral Ecology and Sociobiology, 74, 123.

${ }^{1}$ Department of Biology, University of Ottawa, ON, Canada.

${ }^{2}$ University of St Andrews, Scottish Oceans Institute, Gatty Marine Laboratory, St Andrews KY16 8LB, Scotland, UK.

${ }^{3}$ CNRS, IPHC UMR 7178, Université de Strasbourg, F-67000 Strasbourg, France.

${ }^{4}$ School of Animal, Plant and Environmental Sciences, University of the Witwatersrand, Johannesburg, South Africa.

*Author for correspondence:

pagnani@uottawa.ca

ORCID: 0000-0002-1137-0774

Department of Biology

University of Ottawa

30 Marie Curie, Ottawa, ON, CANADA, K1N 6N5

Tel: (613) 562-5800 x6349

Fax: (613) 562-5486

Running title: Exploration and locomotor performance 


\section{Abstract}

Personality traits (e.g., activity, exploration, boldness) are frequently correlated with each other and with various other traits of biological importance. According to the performance, allocation, and independent models of energy management, the relationship between personality traits and resting metabolic rate (RMR) is predicted to be either positive, negative, or nil. As for the relationship between personality traits and locomotor performance, the trait compensation and co-specialisation hypotheses respectively predict a positive and negative relationship. To test for associations between personality, metabolism, and performance, we studied a wild population of Karoo bush rat (Myotomys unisulcatus) in South Africa. During summer 2018 we captured 45 individuals (38 females and 7 males) a total of 293 times and repeatedly measured docility (time spent immobile during a bag test), exploration (distance moved in an open-field test), sprint speed, and RMR. We found a behavioural syndrome in our population, as more docile individuals covered less distance in the exploration test $(r \pm S E=-0.74 \pm 0.21)$. RMR was not correlated with any trait; therefore, the independent energy management model applies in this population. Fast sprinters were less explorative in the novel environment than slow sprinters $(r \pm S E=-0.41 \pm 0.21)$, going against the prediction of the phenotypic compensation hypothesis and suggesting co-specialisation of these traits. A similar result was previously observed in two other rodent species, suggesting that exploratory behaviour and locomotor performance may interact in an additive instead of compensatory way. Given the apparent complexity of the links between performance, behaviour, and metabolism, more studies are needed in order to understand their relationships.

Keywords: Among-individual correlations, basal metabolic rate, personality, running performance, resting metabolic rate. 


\section{Significance Statement}

57 In this study, we test alternative energy management models and hypotheses predicting

58 different relationships between behavioural, performance, and metabolic traits. Our results

59 support the independent model of energy management, since resting metabolic rate was

60 not correlated with either docility nor exploration. The negative relationship between

61 exploration and sprint speed is counter to the intuitive idea that more explorative individuals

62 should be better equipped to deal with the increased risks of predation, but instead

63 supports the co-specialisation hypothesis. Finally, we emphasize the importance of

64 partitioning the variance in raw measurements as a way to better appreciate variability in

65 measurements of metabolic rate and locomotor performance. Such multilevel analyses

66 provide an idea of the relative variability at among-individual level vs. other levels (tests,

67 trials, and residuals), which might have important implications for the understanding of how

68 factors like stress and motivation might potentially generate or obfuscate relationships

69 between behavioural, performance, and metabolic traits. 


\section{Introduction}

72 The field of animal personality - defined as repeatable individual differences in activity,

73 exploration, boldness, aggressiveness, and sociability - has experienced a major surge in

74 interest over the last 20 years (Stamps 1991; Dingemanse and Réale 2005; Dingemanse et al.

75 2010; Stamps and Groothuis 2010; Carter et al. 2013). Salient features of animal personality

76 studies are 1) the focus on individual variation and 2) the use of standardised tests to

77 measure individual behavioural reactions to various situations (e.g., novel, familiar, and risky

78 situations). Although behavioural tests are sometimes conducted in an unnatural context

79 (e.g., the open-field test), individual differences captured in these tests are thought to relate

80 to behaviours exhibited in various natural situations such as habitat use, predation

81 avoidance, dispersal, or social behaviours (Dingemanse et al. 2003; Dall et al. 2004) and have

82 been validated in many cases (Fraser et al. 2001; Boon et al. 2008; Boyer et al. 2010; van

83 Overveld and Matthysen 2010; Yuen et al. 2016). As such, personality traits have been found

84 to affect fitness components (Dingemanse and Réale 2005; Moiron et al. 2020 but see Smith

85 and Blumstein 2008)

Personality traits are frequently correlated with each other, in which case they can

87 be referred to as behavioural syndromes (Sih et al. 2004). Behavioural syndromes imply limited plasticity in behaviour (Sih et al. 2004). Although individuals may display different levels of aggressiveness depending on contexts, more aggressive individuals typically remain more aggressive in all contexts (i.e., rank order maintained) and are also generally bolder than less aggressive individuals (Riechert and Hedrick 1993). Behavioural syndromes are especially relevant to the field of animal behaviour as they may help us understand the maintenance of inter-individual variation in behaviour. If personality traits are correlated 
across different contexts, personality traits may not evolve independently from each other, but instead as a suite of correlated traits (Price and Langen 1992). Furthermore, personality traits may not only correlate with each other, but also with other traits of biological importance such as circulating hormones levels (Chang et al. 2012), aspects of the immune system (Butler et al. 2012; Monceau et al. 2017), locomotor performance (Careau and Garland 2012) and metabolic rate (Careau et al. 2008).

All biological processes in an organism require energy, for which individuals must match metabolic fuel supply (lipids, carbohydrates, and protein) to ever-changing energy demands (Weber 2011). The rate at which an individual oxidizes substrates to produce energy has been defined as the metabolic rate. Due to the highly variable nature of metabolic rate in response to various factors (e.g., temperature, biosynthesis, activity), a certain degree of standardisation is required to compare metabolic rate among individuals. Basal metabolic rate (BMR) - the lowest rate at which substrates are oxidized by an endotherm to stay alive - is often measured as the $\mathrm{O}_{2}$ consumption of an animal that is alert but resting, fasting (i.e., post-absorptive), not reproducing or growing, within its thermal neutral zone, and is measured during the inactive part of the animal's daily cycle (Speakman 2013). Despite the highly standardised nature of BMR measurements, there usually remains a large degree of inter-individual variation within populations (Speakman et al. 2004). In many circumstances, especially in field studies, it is not possible to meet all of the criteria to measure BMR, in which case measurements are referred to as resting metabolic rate (RMR). BMR and RMR are nevertheless considered analogous traits (hereafter referred to as RMR). The links between RMR and animal personality have been intensely explored over the last decade (Careau et al. 2011; Killen et al. 2011; Le Galliard et al. 2013; Bouwhuis et al. 
117 2014; Gifford et al. 2014; Krams et al. 2017; Chen et al. 2019; Cornwell et al. 2020).

118 According to the allocation model, which assumes that there is a finite amount of energy

119 that an animal can spend on competing processes, behaviours such as activity should be

120 negatively correlated with RMR, as a higher RMR will result in less energy available to spend

121 on activity, and vice versa (Speakman 1997; Careau et al. 2008). Alternatively, according to

122 the performance model, RMR and activity should be positively correlated because more

123 active individuals sustaining higher levels of energy expenditure should require a larger

124 "machinery" (larger organs) which, at rest, leads to a higher RMR (Daan et al. 1990; Careau

125 et al. 2008). Finally, the independent model recognizes that physical activity has a direct

126 impact on daily energy expenditure, but assumes that RMR and physical activity are

127 independent (Careau and Garland 2012).

The behavioural repertoire of an animal is, by definition, confined within a space set

by its performance abilities (Bennett 1989). Performance - the ability of an individual to

perform a task when maximally motivated - includes repeatable traits such as speed,

131 strength, and endurance (Garland and Losos 1994). Intuitively, an individual that can run fast

132 or has a strong bite could behave more boldly and aggressively than an individual that run

133 slow or has a weak bite (Herrel et al. 2009). This intuitive idea corresponds to the "trait

134 compensation" hypothesis developed in the context of co-adaptations between anti-

135 predator behaviour and morphological defence (Dewitt et al. 1999). With respect to

136 locomotor performance, the trait compensation hypothesis received some empirical

137 support. In zebrafish (Danio rerio), artificial selection for boldness resulted in the bold line

138 having higher locomotor performance than the shy line (Kern et al. 2016). In the delicate

139 skink (Lampropholis delicata), bolder individuals with a "hot thermal type" had faster sprint

140 speeds than shyer individuals with a "cold thermal type" (Michelangeli et al. 2018). In the 
141 Asian agamid lizard (Phrynocephalus vlangalii), time spent moving during a novel

142 environment test was positively correlated with endurance (Chen et al. 2019).

143 According to the trait compensation hypothesis, a fast sprinter can take more risks

144 (e.g., forage farther from refuge) because it could potentially escape a predator more easily

145 than a slow sprinter. An alternative possibility is that both behaviour and performance

146 enhance overall protection from predation, which corresponds to the "trait co-

147 specialisation" hypothesis that predicts a negative relationship between boldness and

148 locomotor performance (Dewitt et al. 1999). We are aware of three studies that support the

149 trait co-specialisation hypothesis, all on rodents. In Barbary ground squirrels (Atlantoxerus

150 getulus), escape speed was negatively correlated with time of entrance into the open field

151 (i.e., faster sprinters were shyer; Piquet et al. 2018). Similarly, sprint speed was negatively

152 correlated with distance moved during a novel environment test in Eastern chipmunks

153 (Tamias striatus) (Newar and Careau 2018). In Yellow bellied marmots (Marmota

154 flaviventris), sprint speed was positively correlated with vigilance while foraging (i.e., faster

155 sprinters were more vigilant; Blumstein et al. 2004). Given the contrasting results supporting

156 both the trait compensation and co-specialisation hypotheses, further research is needed on

157 the links between personality and performance, and how these two aspects of the

158 phenotype covary with metabolic rate.

159 Here, we test for associations between behaviour, metabolism, and performance in a

160 wild population of Karoo bush rats (Myotomys unisulcatus) in South Africa. Karoo bush rats

161 are diurnal (crepuscular) central-place foragers for which locomotor performance abilities

162 such as sprint speed are important to rapidly travel across open spaces between bushes and

163 therefore play a functional role in survival. At our field site (see below), Karoo bush rats are 
164 solitary living (JT and CS, unpublished data), which prevents an influence of social status on 165 personality. We repeatedly captured marked individuals and measured different aspects of

166 their personality (exploration and docility), energy metabolism (RMR), and locomotor

167 performance (sprint speed). Such repeated sets of measures of these traits also allowed us

168 to partition phenotypic correlations into the among-individual correlations $\left(r_{\text {ind }}\right.$; correlation

169 between individual means) and within-individual correlations ( $r_{e}$; correlation between

170 deviations from the individual means). Although we found no relationship between

171 personality and RMR (supporting the independent model), we found a negative $r_{\text {ind }}$ between

172 exploration and sprint speed, thus supporting the trait co-specialisation hypothesis.

173

\section{Methods}

175 Study site

176 Karoo bush rats were monitored from February to April 2018 in an area surrounding the

177 Succulent Karoo Research Station in the Goegap Nature Reserve, Northern Cape Province,

178 South Africa $\left(29^{\circ} 41^{\prime} 56^{\prime \prime} \mathrm{S}, 18^{\circ} 1^{\prime} 60^{\prime \prime} \mathrm{E}\right.$, altitude $\left.912 \mathrm{~m}\right)$. The Succulent Karoo is an arid

179 biodiversity hotspot with a mean annual rainfall of $160 \mathrm{~mm}$, our study took place during a

180 drought with $\sim 76 \mathrm{~mm}$ of rainfall for 2018 . At our field site, the minimum night-time and

181 maximum daytime temperatures are respectively -1.5 and $24^{\circ} \mathrm{C}$ during winter and 4 and

$18242^{\circ} \mathrm{C}$ during summer (CS, unpublished data). 
184

185

186

187

188

\section{Captures}

Sherman-like traps baited with a mix of bran flakes, oil, raisins, salt, and freshly cut apples were used to trap individuals around their nests. Traps were set before the sun was illuminating the valley (6:00-7:00) and checked at first after 45min and again after 90min. For every capture done by one of two observers (PA or JT), individuals were removed from the trap and a bag test was performed before any other handling occurred. The bag test consisted of transferring the individual from the trap into a plastic handling bag, where it was suspended at an arm's length for 1 min while the number of seconds spent immobile was measured using two stopwatches (one for the duration of the test and another for the time spent immobile). This test was previously used to capture aspects of docility and freezing behaviour in the presence of humans (Martin and Réale 2008; Newar and Careau 2018). The bag test was not done when individuals were accidently captured by members of another research team working on striped mice ( 47 out of 292 captures), in which case the individuals were identified and directly brought to the laboratory without bag test.

After the bag test, individuals were identified (or tagged if this was the first capture of an individual, see below), sexed, and weighed using a digital scale (KERN EMB 500, 0.1g precision). Upon first capture, individuals were permanently marked using ear-tags (National Band and Tag Co., Newport, KY, USA) for individual recognition, and immediately released.

Ear tagging is a technique considered relatively harmless and more efficient than alternatives techniques of marking, but that can increase tick load (Wood and Slade 1990; Kuenzi et al. 2005; Ostfeld et al. 2017). After the bag test and standard manipulations were done, individuals were either released because they were brought to the lab on the previous 
day (107 out of 245 captures) or placed back into their traps and transported to an adjacent on-site laboratory where aspects of their behaviour, performance, and metabolism were measured. Up to 9 individuals per day were transported to the laboratory, but not all tests were conducted on all individuals on a given day to avoid rapid habituation to the novel environment and because our respirometry system allowed for measuring only 3 individuals per day. Individuals were released at their nest of capture after completing, one, two or the three tests, depending on their last capture date, and were never kept longer than 7 hours in the laboratory. It was not possible to record data blind because our study involved focal animals in the field.

\section{Behavioural test}

Once in the laboratory, the first test conducted was an open-field test (Archer 1973). All open-field tests were done between 9:00 to 10:30. Karoo bush rats were released in a whitepainted rectangle test arena $(80 \times 95 \mathrm{~cm})$, where their behaviour was recorded with a camera (Microsoft LifeCam Cinema H5D-00018) for 5 min. Black curtains were placed around the arena to ensure that the individuals could not see the surroundings and were not disturbed. The software EthoVision XT (Noldus Information Technology, Wagenigen) was used to track the individual and extract the total distance moved.

\section{Performance test}

The second laboratory test, usually conducted between 10:30 to 11:30, was designed to measure sprint speed on a $6 \mathrm{~m}$ long by $12 \mathrm{~cm}$ wide plastic racetrack with marks at $1,2,3,4$, and $5 \mathrm{~m}$ allowing to measure the sprint speed over $4 \mathrm{~m}$ (starting at 1 and ending at 5). 
Individuals were released at the beginning of the racetrack and allowed to explore shelters (square metal box) at both ends of the racetrack where they could rest/hide in between

trials. The individual was then chased by an observer who ran and screamed behind the rat using a piece of cardboard to scratch the surface of the racetrack behind the rat. Videos were recorded using a wide-angle camera at 30 frame per second (DanCoTech A9-DCH-BA).

234 Trials in which the individuals did not run, stopped, or jumped out of the racetrack were discarded. A total of three trials per test were conducted on each rat on a given day. The status of the individual was closely monitored throughout the test to make sure the procedures did not induce any adverse effects (such as injuries or complete exhaustion that could lead to lasting effects after the test ended, which never occurred). Running speed was determined by using the Tracker software (Open Source Physics) by counting frames in between marks. For each test, we extracted the trial that yielded the fastest speed over one meter, this value was retained as the maximum sprint speed for that individual on that day.

Respirometry

244 Respirometry tests were conducted after open-field and sprint speed tests, between 13:00

245 and 16:00. This period corresponds to the non-active phase of the diurnal cycle in Karoo

246 bush rats (they are considered crepuscular and therefore lower their activity in the

247 afternoon to avoid heat; du Plessis et al. 1991). Metabolic rate was measured using a flow-

248 through respirometry system with three chambers and one baseline channel. Ambient air

249 was pumped and directed into a manifold where it was split into 4 different streams. Each

250 individual air stream was directed through a mass-flow meter (FB8, Sables Systems) and sent

251 into one of the 4 chambers (three chambers containing individuals and one empty chamber 
252 as baseline) at a flow rate of $\sim 700 \mathrm{~mL} \cdot \mathrm{min}^{-1}$. Outcoming air was directed through $\mathrm{O}_{2}, \mathrm{CO}_{2}$, and 253 water vapor sensors (FoxBox, RH-300; Sable systems). After monitoring the baseline channel

254 for $5 \mathrm{~min}$, the system sequentially sampled the 3 chambers for 10 min each, after which 255 another baseline measurement was taken. This process was repeated 3 more times, yielding 256 a total of four 10 min samples for each individual on a given day. For each 10 min sample, we 257 extracted the lowest mean $\mathrm{O}_{2}$ consumption over a period of 4:30 min. The lowest of these 258 four estimates was retained as the RMR of that individual on that day. While in the 259 chambers, individuals were monitored using a webcam (Microsoft Livecam HD-3000) to 260 ensure that they were resting (i.e., not moving). We did not discard any estimates as 261 individuals were always immobile for the timestamps corresponding to the lowest $\mathrm{O}_{2}$ 262 consumptions.

Statistical analyses were done using ASReml-R version 3 (Gilmour et al. 2009). All traits were 266 standardised to a mean of 0 and a variance of 1 . Before analysing sprint speed and RMR, we 267 wanted to gain a better understanding of the variability in the raw measurements at various 268 levels. Indeed, variation in running speed occurs at four different levels; among individuals, 269 among tests within individuals, among trials within tests, and among successive meters

270 within trials. To capture variance at each of these levels, we used a multilevel approach, 271 where random effects of 1 ) individual identity (ID) captured among-individual variance $\left(V_{\text {ind }}\right)$,

272 2) ID combined with test captured variance among tests within individuals ( $\left.V_{\text {test }}\right)$, and 3) ID 273 combined with test and trial number captured variance among trials within tests ( $\left.V_{\text {trial }}\right)$. After 274 accounting for these levels of variance, the residual variance $\left(V_{e}\right)$ represented the variance in 
275

276

27 278

running speed between successive meters within trials and measurement error. For metabolic rate, we took 4 repeated measurements per respirometry test; therefore variation in metabolic rate occurs at three different levels; among individuals ( $\left.V_{\text {ind }}\right)$, among tests within individuals $\left(V_{\text {test }}\right)$, and among successive measurements within tests $\left(V_{e}\right)$.

In a second step, we extracted daily maximum running speed (hereafter called sprint speed) and the daily minimum metabolic rate (hereafter called RMR) that we used to calculate repeatability and estimate among- and within-individual correlations. We first ran univariate mixed models to assess the effects of Julian day, sex, and test sequence (i.e., the number of times the individual passed the test) on body mass, docility, distance moved in the open field, sprint speed, and RMR. All univariate mixed models included body mass as a fixed effect (except the one in which body mass was the response variable) and included individual identity as a random effect to partition the phenotypic variance (after conditioning on the fixed effects above) into an among-individual variance ( $\left.V_{\text {ind }}\right)$ and withinindividual variance ( $V_{e}$; residuals). Adjusted repeatability of sprint speed, RMR, time spent immobile in the bag test, and distance moved in the open field were calculated as the ratio $R$ $=V_{\text {ind }} /\left(V_{\text {ind }}+V_{e}\right)$. The approximate standard errors (se) for $R$ were calculated using the delta method using the pin function in nadiv (Wolak 2012).

We then used a multivariate mixed model to assess the among-individual correlations $\left(r_{\text {ind }}\right)$ and the within-individual correlations $\left(r_{e}\right)$ between docility, exploration, sprint speed, and RMR. The multivariate model included the same fixed effects as above (body mass, sex, test sequence, and Julian day) fitted to all traits. A $4 \times 4$ correlation matrix ('corgh' structure in ASReml-R) was fitted at the among-individual level (ID) to estimate $V_{\text {ind }}$ and $r_{\text {ind }}$ between traits. A $4 \times 4$ correlation matrix was also fitted at the residual level to 
estimate $V_{e}$ and $r_{e}$ between traits. The $95 \%$ confidence intervals for $r_{\text {ind }}$ and $r_{e}$ were calculated using profile likelihoods with the proLik function in nadiv (Wolak 2012). Best linear unbiased predictors (BLUPS) were extracted from the multivariate mixed model to obtain a graphic representation of $r_{\text {ind }}$ and $r_{e}$.

ASReml-R uses a model-based missing data augmentation method (more specifically, "full information maximum likelihood") for the estimation of missing values in the response variables of a multivariate mixed model, which allowed us to fully consider all observations made on all individuals throughout the study in our multivariate mixed model. The missing data procedures in ASReml-R can improve the estimation of among-individual correlations and are preferable over "complete cases analyses" (Noble and Nakagawa 2018). Note that although traits were not always all measured on a given day, there was enough overlap between measurements to estimate $r_{e}$ (e.g., sprint speed and RMR were measured 113 times on the same day, sprint speed and exploration were measured 110 times on the same day, and RMR and exploration were measured 87 times on the same day). Our protocol also means that individuals experienced different combinations of testing in the laboratory. We tested the possibility of carry-over effects by creating a dummy variable indicating if the individual was tested in the open field prior to the other measurements, but this variable was not significant for sprint speed and RMR ( $P>0.05$ in both cases). Similarly, a dummy variable indicating if the individual was tested in the race track prior to respirometry did not have a significant effect on RMR $(P>0.05)$. Therefore, we are confident that carry-over effects of sequential testing did not influence the results.

Finally, the multilevel analysis above revealed substantial variance in running speed from one meter to the next within performance trials (see below). Therefore, we wanted to 
321

322

323

324

325

\section{Results}

explore if behaviour and running speed covary differently at different points along the race track. We fitted a second multivariate model using the same fixed and random effects as above (body mass, sex, test sequence, and Julian day, ID) in which the response variables were the two behavioural traits and running speeds at each meter (speed 1, speed 2, speed 3 and speed 4) of the race track. A $6 \times 6$ correlation matrix was fitted at the amongindividual and residual levels to provide the $r_{\text {ind }}$ and $r_{e}$ between behavioural traits and running speed at each meter of the race track.

\section{Descriptive statistics}

We captured and tested a total of 45 individuals ( 38 females, 7 males), of which 37 were repeatedly tested ( 8 individuals were only tested once). A total of 244 bag tests, 119 openfield tests, 123 respirometry tests, and 177 sprint speed tests were performed with repeated measures varying between 1 to 14 for each individual (see Table 1).

Time spent immobile during the bag test averaged 53.7 seconds (see Table 1 for descriptive statistics). While many individuals remained "frozen" (immobile) for the whole test, a few individuals were more active with the shortest time spent immobile being 5.8 seconds. During the open-field test, most rats moved around the walls of the arena, avoiding the centre and moved over relatively short distances $(13 \mathrm{~m})$ with some individuals showing higher levels of exploration than others (range: 1-40 m). Sprint speed ranged between 1.5 to $4.3 \mathrm{~m} \cdot \mathrm{s}^{-1}$ for an average of $3.2 \mathrm{~m} \cdot \mathrm{s}^{-1}$ which is within the range of the sprint speed recorded on similar sized rodents (Djawdan and Garland 1988). RMR ranged from 0.62 to $2 \mathrm{mlO}_{2} \cdot \mathrm{min}^{-1}$ 
343 with an overall mean of $1.2 \mathrm{mlO}_{2} \cdot \mathrm{min}^{-1}$, which is in accordance with values measured for

344 similar-sized grazing rodents (Bozinovic 1992).

347 Considering all running speed tests and trials, we found that $35.1 \%$ of the variance was due

348 to differences between individuals (as estimated by the $V_{\text {ind }}$ random effect), while $11.4 \%$ was

349 due to differences between days within individuals (as estimated by the $V_{\text {test }}$ component)

350 (Table S1). Additionally, only $6.2 \%$ of the variance was due to differences between trials

351 within days (as estimated by $V_{\text {trial }}$ ). Finally, $52 \%$ of the variance in running speed occurred

352 among meters within trials (as estimated by $V_{e}$ ). The analysis of sprint speed below is based

353 on the fastest speed recorded over one meter on a given test (day).

354 Considering all respirometry tests, $31.7 \%$ of the variance in metabolic rate was due to 355 differences between individuals $\left(V_{\text {ind }}\right)$, whereas $36.2 \%$ was due to differences between days 356 within individuals ( $V_{\text {test }}$ ) (Table S1). Finally, 31.9\% of the variance occurred among successive 357 measurements within trials, representing measurement error and variation in metabolic rate 358 (probably due to activity and stress) when rats were restrained within metabolic chambers.

359 The lowest metabolic rate value recorded over the four sampling periods on a given test 360 (day) was extracted as RMR, and which always corresponded periods of inactivity.

363 Males were heavier than females (Table 2A; Fig. 1A). Sex also had a significant effect on 364 sprint speed with males showing slower sprint speed than females (Table 2D; Fig. 1B). Body 
365

366

367

368

369

370

371

372

373

374

375

376

377

378

379

380

381

382

383

384

385

386

387

mass did not affect docility, exploration, and sprint speed (Table 2), but as expected there was a positive effect on RMR (Table 2E; Fig. 1C). Test sequence had a negative effect on distance moved in the open field (Table $2 \mathrm{C}$ ), especially between the first and second measurements (Fig. 1D), suggesting an habituation effect. Test sequence also had a positive effect on sprint speed (Table 2D; Fig. 1E), suggesting that individuals would perform better as they repeated the sprint speed test. Finally, Julian day had a positive effect on RMR (Table 2E).

\section{Among- and within-individual correlations}

After taking the above-mentioned fixed effects into account, all traits were significantly repeatable, with estimates ranging from $R \pm \mathrm{SE}=0.903 \pm 0.021$ for body mass to $R \pm \mathrm{SE}=$ $0.203 \pm 0.115$ for RMR (Fig. 2). None of the within-individual correlations were significant (Table 3). At the among-individual level, however, there were two significant correlations (Table 3). There was a strong negative correlation between docility and exploration $\left(r_{\text {ind }} \pm\right.$ $\mathrm{SE}=-0.740 \pm 0.216)$ indicating that individuals who spent more time immobile during the bag test moved over shorter distances during the open-field test (Fig. 3A). There was also a negative correlation between sprint speed and exploration $\left(r_{\text {ind }} \pm \mathrm{SE}=-0.399 \pm 0.213\right)$, indicating that the fastest sprinters moved over shorter distances during the open-field test (Fig. 3B).

\section{Behaviour vs running speed}

Here, we consider all speed measurements from the trial for which sprint speed was extracted and look at the covariance with behaviour. As can be expected, consecutive 
speeds at each meters were correlated with each other with estimates ranging from 0.999 to

0.854 at the among-individual level and 0.563 to 0.230 at the within-individual level (Table

S2). At the among-individual level, exploration was negatively correlated with running speed

391

392

393

394 at all positions of the race track, with significant relationships at 3 of the 4 positions (first, second and fourth meter; Table S2; Fig. 4). None of the within-individual correlations were significant between exploration and running speed (Table S2; Fig. 4). By contrast, docility was not correlated with running speed at the among-individual level, but the withinindividual correlations changed as function of the position of the race track; the only significant within-individual correlation was with running speed recorded over the first meter of the race track (Table S2; Fig. 4).

\section{Discussion}

Our objective was to test for correlations between personality, performance, and metabolic rate at the among- and within-individual levels. As previously found in many studies on rodents, we found a behavioural syndrome in our population in which docility and exploration were negatively correlated at the among-individual level. We did not find correlations between RMR and any other traits, including docility and exploration.

Therefore, our results support the independent model (Careau and Garland 2012). We found a negative correlation between exploration and sprint speed at the among-individual level. Altogether, our results and those from three other studies on rodents (Blumstein et al. 2004; Newar and Careau 2018; Piquet et al. 2018) provide empirical support for the idea that personality and performance traits are co-specialised. 
412 If performance determines what individuals can do behaviourally, higher sprinting abilities

413 should allow individuals to take more risks, because those individuals are better equipped to

414 escape potentially dangerous situations (Careau and Garland 2012). Interestingly, however,

415 we found that the individuals with the highest locomotor performance (fastest sprinters)

416 were also less explorative in the open-field test. This is the opposite result to what is

417 predicted from the trait compensation hypothesis (Dewitt et al. 1999). Instead, the negative

418 correlation between sprint speed and exploratory behaviour lends support to the trait co-

419 specialisation hypothesis (see Dewitt et al. 1999), where both traits additively reinforce

420 protection from predators. Although trait compensation seems to be one of the most

421 commonly observed pattern among species between behavioural and morphological

422 defenses, whereby species with larger defenses (e.g., shells) are bolder and/or more

423 explorative (Mikolajewski and Johansson 2004; but see Hossie et al. 2017), studies

424 conducted so far on the functional relationship between behaviour and performance at the

425 individual level suggest that the prevailing pattern is trait co-specialisation in mammals (this

426 study; Blumstein et al. 2004; Newar and Careau 2018; Piquet et al. 2018). In other words,

427 shy or less explorative individuals are less prone to encounter a predator, and in the event of

428 an encounter, their higher sprinting abilities further increase chance of successful escape,

429 and therefore survival.

430 An alternative explanation for the negative relationship between sprint speed and

431 exploratory behaviour could be that the stress response of the individuals covary with

432 individual variation in motivation during the performance tests. For example, if shy

433 individuals are more fearful and anxious than bold individuals, they might be less motivated 
434 to explore the arena during the novel environment test, but more motivated to run down

435 the race track at their fastest when being chased. For that scenario to be true, however,

436 there has to be individual variation in motivation, while performance protocols are typically

437 designed to eliminate such variation. Nevertheless, Losos et al. (2002) identified motivation

438 as "the major problem bedevilling studies of performance", as previous studies showed that

439 some individuals do not use their maximal capacities during the tests (Pough 1989; Garland

440 and Losos 1994). Sub-maximal trials - when animals are judged as not having performed to

441 their maximum - are usually excluded from performance studies, but deciding which trials to

442 exclude may vary across studies. Losos et al. (2002) pointed out that $49 \%$ of the 65 studies

443 published between 1979 and 1999 on lizard sprinting abilities did not mention sub-maximal

444 trials, and that only a few studies clearly stated that they excluded these trials. Although we

445 excluded all sub-maximal trials, no individual was excluded from our study. Nevertheless,

446 some variation in motivation must remain among and within retained trials, and, because of

447 the potential covariance it can induce between performance and behaviour, a better

448 appreciation of variation in raw performance measures is warranted (Berberi and Careau

449 2019).

450

451

Variation in running speed across levels

452 To our knowledge, only two studies so far have followed a multilevel approach (Araya-Ajoy

453 et al. 2018) and used extra random effects to partition variance in running speed across

454 different temporal scales (Berberi and Careau 2019; Lailvaux et al. 2019). In these studies,

$45517-19 \%$ of the variance in running speed occurred at the among-individual level, whereas

$45635 \%$ of the variance occurred at that level in our dataset. These relatively low estimates of 
457 long-term repeatability imply that many repeated tests per individual are required to

458 properly quantify individual differences in locomotor performance. In contrast to Berberi

459 and Careau (2019) and Lailvaux et al. (2019), we retained running speed measures taken at

460 each meter of the racetrack. Interestingly, the levels with the lowest amount of variance

461 were $V_{\text {test }}$ and $V_{\text {trial. }}$. Therefore, running speed did not vary much between tests conducted on

462 a given individual throughout the season and between trials conducted on a given day,

463 which is quite encouraging because it suggests that variation in motivation was low at these

464 levels.

465 About half of the variance in running speed resided in the $V_{e}$ component, which

466 consists of variation in motivation and measurement error. To reduce measurement error in

467 our running speed measurements, we should have used a high speed camera that records at

468 a faster rate than 30 frames per sec. Still, variation in motivation from meter to meter within

469 trials was evident (PA, pers. obs.), which gave us the idea of exploring how behaviour

470 covaries with running speeds recorded at different positions of the race track. We found that

471 docility was correlated with running speed recorded over the first meter of the race track at

472 the within-individual level. Therefore, on a given test day, an individual who remained more

473 immobile during the bag test than its own average ran faster than usual on the first meter of

474 the racetrack. This suggests that individuals who were, for unknown reasons, more fearful of

475 humans on a given day, froze for a longer period during the bag test and displayed a higher

476 acceleration when running away from the chaser. Given that docility and speed were

477 measured in different locations and using different tools, correlated measurement error is

478 unlikely to have caused the $r_{e}$ between the two traits. Therefore, the $r_{e}$ must have been

479 caused by correlated phenotypic plasticity with respect to factors that were unaccounted for

480 in our experiment (Brommer and Kluen 2012; Careau and Wilson 2017a, b). Note that the 
481 relationship between docility and speed was not apparent in the analyses of sprint speed

482 (Table 3) because the fastest running speed is usually reached in the second and third

483 meters of the race track. Hence, our results show the insights that can be gained from

484 analysing raw running performance measurements, especially when trying to relate

485 performance to behaviours that involve reactions to human presence.

486

487 Repeatability and behavioural syndrome

488

489

490

491

492

493

494

495

496

497

498

499

500

501

502

503

Repeatability of behavioural traits is generally higher in the field than in the laboratory, presumably because individuals live in heterogenous environments that permanently influence their behaviour, increasing among-individual differences and therefore repeatability (Bell et al. 2009). In our case, however, adjusted repeatability was $R=0.319$ for docility and $\mathrm{R}=0.30$ for exploration, respectively, which is slightly under the reported average repeatability of behaviours ( $R=0.37$ ) (Bell et al. 2009). We also found that the more explorative individuals were less docile. Similar behavioural syndromes have been previously observed in a number of other populations of mammals between docility and exploration (Montiglio et al. 2012; Careau et al. 2015) and between docility, exploration, and activity (Petelle et al. 2015). A similar behavioural syndrome is also exhibited in birds, between docility (assessed with a "back test") and exploration (Hall et al. 2015) and between docility, aggressivity, and breathing rate (Brommer and Kluen 2012). Thus, the behavioural syndrome we found in bush Karoo rats is very similar to what has been reported for many other species.

These behavioural syndromes appears to be reflective of the "flight or fight" response, and have been associated with the proactive-reactive continuum of coping style 
strategies (Koolhaas et al. 1999). According to the literature on coping styles, individuals

505

506

507

508

509

510

511

512

513

514

515

516

517

518

519

520

521

522

523

524

525

526

consistently differ in their physiological and behavioural response towards stressful

situations. Proactive individuals tend to interact with the stressor, while reactive individuals

tend to avoid it. Applying this idea to our species, proactive individuals were likely those who moved more in the handling bag trying to escape (therefore being less docile), and who also travelled longer distances in the open-field test (being more explorative). By contrast, reactive individuals were likely those who froze during the bag test and did not travel long distances in the open-field test. More stress-related measures are needed to confirm the associations between docility and exploration behaviour with coping styles in our species.

\section{Lack of relationship with $R M R$}

RMR has been previously found to be a repeatable trait in many taxa, with an average estimate of $R=0.39$ in mammals (White et al. 2013). In this study, the repeatability of RMR was $\mathrm{R}=0.203$ after controlling for date, body mass, sex, and test sequence. In other words, only $\approx 20 \%$ of the total variance in RMR was attributed to differences among individuals and $\approx 80 \%$ of the variance was due to within-individual variation (plasticity) and measurement error. Generally, the repeatability of metabolic rate declines with increasing time between measurement (White et al. 2013), but we think this is an unlikely explanation for the relatively low $R$ observed in our study considering the number of repeated measures we took over a relatively short field season (February $2^{\text {nd }}$ to May $21^{\text {st }}$ ). The relatively low repeatability of RMR might be explained by the fact that this study was conducted on wildcaught animals where natural conditions (i.e., food availability and predation risk) varying within individuals affect differently the expression of the metabolism, compared to more 
527 stable laboratory conditions (Dingemanse et al. 2009; Kontiainen et al. 2009; Auer et al.

528 2016). The field conditions also forced us to use relatively short respirometry tests (i.e.,

529 animals were only kept $4 \mathrm{~h}$ in the metabolic chambers), which might have amplified the

530 influence of stress in our RMR measures.

531 We did not find correlations between RMR and any of the other traits we measured

532 (docility, exploration, or sprint speed). Given the relatively low repeatability of RMR and

533 number of individuals sampled, it is possible that we had low power to detect any

534 relationship with RMR. Nevertheless, our results support neither the allocation nor the

535 performance model; instead, it appears the independent model applies in our population, in

536 which RMR and behaviours are not correlated but where non-resting measurements of

537 metabolism (such as the daily energy expenditure) are expected to be correlated to

538 behaviour (Careau and Garland 2012). A recent meta-analysis on the covariance between

539 RMR and behaviour pointed out that RMR was positively correlated with behaviours that

540 likely have consequences for energy gain (e.g., foraging), or expenditure (e.g., sustained

541 running speed), but was not correlated with behaviours that have uncertain energetic

542 outcomes such as the two behavioural traits used in this study (Mathot et al. 2019).

543 Although RMR and behaviours are not correlated in the independent model, behavioural

544 traits still have an influence on the non-resting part of the energy budget (e.g., (Careau et al.

545 2015). In such cases where the independent model applies, the energetic impacts of

546 personality would only be detectable through the measurement of daily energy expenditure,

547 which includes the energetic costs of activity in addition to basal costs of living (and other

548 costs, e.g., thermoregulation). 


\section{Conclusions}

551 Although it is intuitive to think that bolder and more explorative individuals should be better

552 equipped to deal with the increased risks resulting from those behaviours (trait

553 compensation), empirical evidence in rodents show this is not the case. Instead, it appears

554 that sprint speed is co-specialised with vigilance and exploratory behaviour in rodents (this

555 study; Blumstein et al. 2004; Newar and Careau 2018; Piquet et al. 2018). Future research

556 should tackle the implications of trait co-specialisation for the pace of life, especially survival

557 in prey species. It will also be important to evaluate the contribution of motivation

558 underlying individual co-variation in personality and performance. Doing so might involve

559 using methods for measuring performance with different levels of stress, for exemple tests

560 that rely on individual's survival instincts (i.e., forced swimming), tests with human-induced

561 stress, and tests where individuals perform without being forced. Finally, it will be important

562 to continue partitioning variance in raw performance measurements to get a better sense of

563 where most of the variation occurs.

564

\section{Acknowledgments}

566 We are grateful for the support of Goegap Nature Reserve, Richard Askew, Florian Drouard,

567 and Pauline Vuarin for their help during data collection, and especially to Jennifer Thomson

568 for her deep involvement during data collection and trapping setup. We also thank two

569 anonymous reviewers for their constructive comments on a previous draft of this

570 manuscript. This study was made possible by the administrative and technical support of the

571 Succulent Karoo Research Station (registered South African NPO 122- 134). 


\section{Declarations}

\section{Funding}

574 Funding was provided by the University of the Witwatersrand and the Natural Sciences and

575 Engineering Research Council of Canada.

\section{Conflict of interest}

577 We have no conflict of interest to declare.

\section{Ethics approval}

579 All procedures were approved by the University of Ottawa Animal Care Committee (protocol

580 \#BL-2659), certified by the Canadian Council on Animal Care. All applicable international,

581 national, and/or institutional guidelines for the use of animals were followed

582 Consent to participate

583 Not applicable.

\section{Consent for publication}

585 Not applicable.

\section{Availability of data and material}

587 Databases used in this study are available as supplementary material.

\section{Code availability}

589 The code used to perform the statistical analyses is available as supplementary material. 


\section{References}

591 Archer J (1973) Tests for emotionality in rats and mice: A review. Anim Behav 21:205-235

592 Auer SK, Bassar RD, Salin K, Metcalfe NB (2016) Repeatability of metabolic rate is lower for 593 animals living under field versus laboratory conditions. J Exp Biol 219:631-634

594 Bell AM, Hankison SJ, Laskowski KL (2009) The repeatability of behaviour: a meta-analysis. $595 \quad$ Anim Behav 77:771-783

596 Bennett A (1989) Integrated Studies of Locomotor Performance. In: Wake DB, Roth G (eds) 597 Complex organismal functions: integration and evolution in vertebrates. John Wiley \& 598 Sons Ltd, Chichester, pp 191-202

599 Berberi I, Careau V (2019) Performance trade-offs in wild mice. Oecologia 191:11-23

600 Blumstein DT, Runyan A, Seymour M, et al (2004) Locomotor ability and wariness in yellow601 bellied marmots. Ethology 110:615-634

Boon AK, Réale D, Boutin S (2008) Personality, habitat use, and their consequences for survival 603 in North American red squirrels Tamiasciurus hudsonicus. Oikos 117:1321-1328

604 Bouwhuis S, Quinn JL, Sheldon BC, Verhulst S (2014) Personality and basal metabolic rate in a $605 \quad$ wild bird population. Oikos 123:56-62

606 Boyer N, Réale D, Marmet J, et al (2010) Personality, space use and tick load in an introduced 607 population of Siberian chipmunks Tamias sibiricus. J Anim Ecol 79:538-547

608 Bozinovic $F$ (1992) Rate of basal metabolism of grazing rodents from different habitats. Am 609 Soc Mammal 73:379-384

610 Brommer JE, Kluen E (2012) Exploring the genetics of nestling personality traits in a wild 
612 Butler MW, Toomey MB, McGraw KJ, Rowe M (2012) Ontogenetic immune challenges shape 613 adult personality in mallard ducks. Proc R Soc Lond B 279:326-333

614 Careau V, Garland T (2012) Performance, personality, and energetics: correlation, causation, 615 and mechanism. Physiol Biochem Zool 85:543-571

616 Careau V, Montiglio PO, Garant D, et al (2015) Energy expenditure and personality in wild 617 chipmunks. Behav Ecol Sociobiol 69:653-661

618 Careau V, Thomas D, Humphries MM, Réale D (2008) Energy metabolism and animal. Oikos $619 \quad 117: 641-653$

620 Careau V, Thomas D, Pelletier F, et al (2011) Genetic correlation between resting metabolic 621 rate and exploratory behaviour in deer mice (Peromyscus maniculatus). J Evol Biol 622 24:2153-2163

623 Careau V, Wilson RS (2017a) Performance trade-offs and ageing in the 'world's greatest 624 athletes.' Proc R Soc B 284:20171048

625 Careau V, Wilson RS (2017b) Of uberfleas and krakens: Detecting trade-offs using mixed 626 models. Integr Comp Biol 57:362-371

627 Carter AJ, Feeney WE, Marshall HH, et al (2013) Animal personality: What are behavioural 628 ecologists measuring? Biol Rev 88:465-475

629 Chang C, Li CY, Earley RL, Hsu Y (2012) Aggression and related behavioral traits: The impact of 630 winning and losing and the role of hormones. Integr Comp Biol 52:801-813

631 Chen J, Qi Y, Wu Y, Wang X, Tang Y (2019) Covariations between personality behaviors and 

metabolic/performance traits in an Asian agamid lizard (Phrynocephalus vlangalii). PeerJ

633 e7205

634 635

647

648

649

650

Cornwell TO, McCarthy ID, Biro PA (2020) Integration of physiology, behaviour and life history traits: personality and pace of life in a marine gastropod. Anim Behav 163:155-162

Daan S, Masman D, Groenewold A (1990) Avian basal metabolic rates: Their association with body composition and energy expenditure in nature. Am J Physiol-Reg I 259:R333-R340

Dall SRX, Houston AI, McNamara JM (2004) The behavioural ecology of personality: Consistent individual differences from an adaptive perspective. Ecol Lett 7:734-739

Dewitt TJ, Sih A, Hucko JA (1999) Trait compensation and cospecialization in a freshwater snail: size , shape and antipredator behaviour. Anim Behav 58:397-407

Dingemanse NJ, Both C, van Noordwijk AJ, et al (2003) Natal dispersal and personalities in great tits (Parus major). Proc R Soc Lond B 270:741-747

Dingemanse NJ, Kazem AJN, Réale D, Wright J (2010) Behavioural reaction norms: animal personality meets individual plasticity. Trends Ecol Evol 25:81-89

Dingemanse NJ, Réale D (2005) Natural selection and animal personality. Behaviour 11591184

Dingemanse NJ, Van Der Plas F, Wright J, et al (2009) Individual experience and evolutionary history of predation affect expression of heritable variation in fish personality and morphology. Proc R Soc Lond B 276:1285-1293

651 Djawdan M, Garland T (1988) Maximal running speeds of bipedal and quadrupedal rodents.

652 Am Soc Mammal 69:765-772 
653 du Plessis A, Kerley GIH, Winter PED (1991) Dietary patterns of two herbivorous rodents:

654 Otomys unisulcatus and Parotomys brantsii in the Karoo. S Afr J Zool 26:51-54

655 Fraser DF, Gilliam JF, Daley MJ, et al (2001) Explaining leptokurtic movement distributions:

656 Intrapopulation variation in boldness and exploration. Am Nat 158:124-135

657 Garland T Jr, Losos JB (1994) Ecological morphology of locomotor performance in squamate 658 reptiles. In: Wainwright PC, Reilly S (eds) Ecological Morphology: Integrative Organismal 659 Biology. University of Chicago Press, Chicago, pp 240-302

660 Gifford ME, Clay TA, Careau V (2014) Individual (Co)variation in standard metabolic rate, 661 feeding rate, and exploratory behavior in wild-caught semiaquatic salamanders. Physiol $662 \quad$ Biochem Zool 87:384-396

663 Gilmour AR, Gogel BJ, Cullis BR, Thompson R (2009) Asreml. Asreml 33:3-8

664 Hall ML, van Asten T, Katsis AC, et al (2015) Animal personality and pace-of-life syndromes: 665 Do fast-exploring fairy-wrens die young? Front Ecol Evol 3:28

666 Herrel A, Andrade DV, De Carvalho JE, et al (2009) Aggressive behavior and performance in 667 the tegu lizard Tupinambis merianae. Physiol Biochem Zool 82:680-685

668 Hossie T, Landolt K, Murray DL (2017) Determinants and co-expression of anti-predator 669 responses in amphibian tadpoles: a meta-analysis. Oikos 126:173-184

670 Kern EMA, Robinson D, Gass E, et al (2016) Correlated evolution of personality, morphology 671 and performance. Anim Behav 117:79-86

672 Killen SS, Marras S, Mckenzie DJ (2011) Fuel, fasting, fear: Routine metabolic rate and food 673 deprivation exert synergistic effects on risk-taking in individual juvenile European sea 
675 Kontiainen P, Pietiäinen H, Huttunen K, et al (2009) Aggressive ural owl mothers recruit more 676 offspring. Behav Ecol 20:789-796

677 Koolhaas JM, Korte SM, de Boer SF, et al (1999) Coping styles in animals: Current status in 678 behavior and stress- physiology. Neurosci Biobehav Rev 23:925-935

679 Krams IA, Niemelä PT, Trakimas G, et al (2017) Metabolic rate associates with, but does not 680 generate covariation between, behaviours in western stutter-trilling crickets, Gryllus 681 integer. Proc R Soc B 284:20162481

682 Kuenzi AJ, Zumbrum MM, Hughes K (2005) Ear tags versus passive integrated transponder 683 (PIT) tags for effectively marking deer mice. Intermt J Sci 11:66-70

684 Lailvaux SP, Cespedes AM, Houslay TM (2019) Conflict, compensation, and plasticity: Sex685 specific, individual-level trade-offs in green anole (Anolis carolinensis) performance. J Exp $686 \quad$ Zool A 331:280-289

687 Losos JB, Creer DA, Schulte JA (2002) Cautionary comments on the measurement of maximum $688 \quad$ locomotor capabilities. J Zool 258:57-61

689 Le Galliard JF, Paquet M, Cisel M, Montes-Poloni L (2013) Personality and the pace-of-life 690 syndrome: Variation and selection on exploration, metabolism and locomotor 691 performances. Funct Ecol 27:136-144

692 Martin JGA, Réale D (2008) Temperament, risk assessment and habituation to novelty in 693 eastern chipmunks, Tamias striatus. Anim Behav 75:309-318

694 Mathot KJ, Dingemanse NJ, Nakagawa S (2019) The covariance between metabolic rate and 

behaviour varies across behaviours and thermal types: meta-analytic insights. Biol Rev 94:1056-1074

697 698

699

700

701

702

703

704

705

706

707

708

709

710

711

712

713

714

715

716

Michelangeli M, Goulet CT, Kang HS, et al (2018) Integrating thermal physiology within a syndrome: Locomotion, personality and habitat selection in an ectotherm. Funct Ecol 32:970-981

Mikolajewski DJ, Johansson F (2004) Morphological and behavioral defenses in dragonfly larvae: Trait compensation and cospecialization. Behav Ecol 15:614-620

Moiron M, Laskowski KL, Niemelä PT (2020) Individual differences in behaviour explain variation in survival: a meta-analysis. Ecol Lett 23:399-408

Monceau K, Dechaume-Moncharmont FX, Moreau J, et al (2017) Personality, immune response and reproductive success: an appraisal of the pace-of-life syndrome hypothesis. J Anim Ecol 86:932-942

Montiglio PO, Garant D, Pelletier F, Réale D (2012) Personality differences are related to longterm stress reactivity in a population of wild eastern chipmunks, Tamias striatus. Anim Behav 84:1071-1079

Newar SL, Careau V (2018) The fast and the curious: locomotor performance and exploratory behaviour in eastern chipmunks. Behav Ecol Sociobiol 72:27

Noble DWA, Nakagawa S (2018) Planned missing data design: stronger inferences, increased research efficiency and improved animal welfare in ecology and evolution. bioRxiv, https://doi.org/10.1101/247064

Ostfeld RS, Miller MC, Schnurr J (2017) Ear tagging increases tick (Ixodes dammini) infestation rates of white-footed mice (Peromyscus leucopus). J Mammal 74:651-655 
717 Petelle MB, Martin JGA, Blumstein DT (2015) Heritability and genetic correlations of 718 personality traits in a wild population of yellow-bellied marmots (Marmota flaviventris). 719 J Evol Biol 28:1840-1848

720 Piquet JC, López-Darias M, van der Marel A, et al (2018) Unraveling behavioral and pace-of721 life syndromes in a reduced parasite and predation pressure context: personality and 722 survival of the Barbary ground squirrel. Behav Ecol Sociobiol 72:147

723 Pough FH (1989) Organismal performance and Darwinian fitness: approaches and 724 interpretations. Physiol Zool 62:199-236

725 Price T, Langen T (1992) Evolution of correlated characters. Trends Ecol Evol 7:307-310

726 Riechert SE, Hedrick AV (1993) A test for correlations among fitness-linked behavioural traits 727 in the spider Agelenopsis aperta (Araneae, Agenelidae). Anim Behav 46:669-675

728 Sih A, Bell AM, Johnson JC, Ziemba RE (2004) Behavioral syndromes: an intergrative overiew. $729 \quad$ Q Rev Biol 79:241-77

730 Smith BR, Blumstein DT (2008) Fitness consequences of personality: A meta-analysis. Behav $731 \quad$ Ecol 19:448-455

732 Speakman J (1997) Factors influencing the daily energy expenditure of small mammals. Proc $733 \quad$ Nutr Soc 56:1119-1136

734 Speakman JR, Król E, Johnson MS (2004) The functional significance of individual variation in 735 basal metabolic rate. Physiol Biochem Zool 77:900-915

736 Stamps J, Groothuis TGG (2010) The development of animal personality: Relevance, concepts 737 and perspectives. Biol Rev 85:301-325 
738 Stamps JA (1991) Why evolutionary issues are reviving interest in proximate behavioral

739 mechanisms. Integr Comp Biol 31:338-348

740 van Overveld T, Matthysen E (2010) Personality predicts spatial responses to food

741 manipulations in free-ranging great tits (Parus major). Biol Lett 6:187-190

742 Weber JM (2011) Metabolic fuels: Regulating fluxes to select mix. J Exp Biol 214:286-294

743 White CR, Schimpf NG, Cassey P (2013) The repeatability of metabolic rate declines with time.

$744 \quad J$ Jxp Biol 216:1763-1765

745 Wolak ME (2012) Nadiv: An R package to create relatedness matrices for estimating non-

$746 \quad$ additive genetic variances in animal models. Methods Ecol Evol 3:792-796

747 Wood MD, Slade NA (1990) Comparison of ear-tagging and toe-clipping in prairie voles,

$748 \quad$ Microtus ochrogaster. J Mammal 71:252-255

749 Yuen $\mathrm{CH}$, Pillay N, Heinrichs M, et al (2016) Personality traits are consistent when measured 750 in the field and in the laboratory in African striped mice (Rhabdomys pumilio). Behav Ecol $751 \quad$ Sociobiol 70:1235-1246

752 
753 Table 1 Descriptive statistics for body mass (measured in the field), docility (time spent

754 immobile during a 1-min bag test), exploration (distance moved in a 5 min open-field test),

755 sprint speed (fastest speed reached over 1 meter on a given day), and resting metabolic rate

756 (RMR; lowest $\mathrm{O}_{2}$ consumption over $4.5 \mathrm{~min}$ ) in Karoo bush rats in the Goegap Nature

757 Reserve (South Africa, 2018), including the number of individuals sampled ( $\left.N_{\mathrm{ID}}\right)$, total

758 number of observations ( $\left.n_{\text {obs }}\right)$, units, mean, standard deviation $(\mathrm{sd})$, and range (minimum to

759 maximum)

\begin{tabular}{llllll}
\hline & Body mass & Docility & Exploration & Sprint speed & RMR \\
\hline$N_{\text {ID }}$ & 45 & 44 & 45 & 44 & 44 \\
$n_{\text {obs }}$ & 285 & 244 & 119 & 177 & 123 \\
Units & $\mathrm{g}$ & $\mathrm{sec}$ & $\mathrm{cm}$ & $\mathrm{m} \cdot \mathrm{s}^{-1}$ & $\mathrm{mlO}_{2} \cdot \mathrm{min}^{-1}$ \\
Mean & 90.60 & 53.67 & 1309.65 & 3.22 & 1.20 \\
sd & 15.15 & 11.89 & 8.89 & 0.53 & 0.30 \\
Min & 50.20 & 5.80 & 1.00 & 1.54 & 0.62 \\
Max & 127.60 & 60.00 & 4008.02 & 4.29 & 2.03 \\
\hline
\end{tabular}

760

761 
762 Table 2 Effects of sex, test sequence, and Julian day on A) body mass, B) docility (time spent

763 immobile during bag test), C) exploration (distance moved in a 5 min open-field test), D)

764 sprint speed (fastest speed reached over 1 meter on a given day), and E) resting metabolic

765 rate (RMR) in 45 Karoo bush rats, as estimated in separate univariate mixed models. Body

766 mass was also included as a covariate in B-E. Shown are the estimates $( \pm \mathrm{SE})$, denominator

767 degrees of freedom ( $\left.d f_{\text {den }}\right)$, Wald $F$-statistic, and $P$ values. Bold values are significant

768 estimates (see Table 1 for sample size, Fig. 2 for variance estimates, and Table 3 for

769 correlations obtained from the multivariate model)

\begin{tabular}{|c|c|c|c|c|c|}
\hline Trait Source & Estimate & $\pm S E$ & $d f_{\text {den }}$ & $F$ & $P$ \\
\hline \multicolumn{6}{|l|}{ A) body mass } \\
\hline Intercept & 0.199 & \pm 0.190 & & & \\
\hline $\operatorname{Sex}_{[m]}$ & 0.958 & \pm 0.395 & 42.5 & 5.9 & 0.0196 \\
\hline Test sequence & 0.000 & \pm 0.011 & 255.8 & 0.0 & 0.9895 \\
\hline Julian day & -0.002 & \pm 0.002 & 259.2 & 1.5 & 0.2164 \\
\hline \multicolumn{6}{|l|}{ B) docility } \\
\hline Intercept & 0.314 & \pm 0.635 & & & \\
\hline $\operatorname{Sex}_{[m]}$ & 0.034 & \pm 0.303 & 35.7 & 0.0 & 0.9118 \\
\hline Body mass & -0.005 & \pm 0.007 & 73.1 & 0.7 & 0.4214 \\
\hline Test sequence & -0.005 & \pm 0.033 & 100.3 & 0.0 & 0.8811 \\
\hline Julian day & 0.002 & \pm 0.005 & 90.6 & 0.2 & 0.6752 \\
\hline \multicolumn{6}{|l|}{ C) exploration } \\
\hline Intercept & 1.111 & \pm 0.622 & & & \\
\hline $\operatorname{Sex}_{[m]}$ & -0.033 & \pm 0.313 & 40.5 & 0.0 & 0.9171 \\
\hline Body mass & -0.003 & \pm 0.006 & 101.3 & 0.3 & 0.6021 \\
\hline Test sequence & -0.361 & \pm 0.094 & 100.2 & 14.6 & 0.0002 \\
\hline Julian day & -0.001 & \pm 0.005 & 72.8 & 0.1 & 0.7951 \\
\hline \multicolumn{6}{|l|}{ D) sprint speed } \\
\hline Intercept & -0.185 & \pm 0.346 & & & \\
\hline $\operatorname{Sex}_{[\mathrm{m}]}$ & -1.043 & \pm 0.339 & 40.3 & 9.5 & 0.0037 \\
\hline Body mass & 0.003 & \pm 0.002 & 147.1 & 1.6 & 0.2148 \\
\hline Test sequence & 0.041 & \pm 0.016 & 170.8 & 6.4 & 0.0120 \\
\hline Julian day & -0.003 & \pm 0.005 & 167.4 & 0.3 & 0.5696 \\
\hline \multicolumn{6}{|l|}{ E) RMR } \\
\hline Intercept & -4.685 & \pm 0.499 & & & \\
\hline $\operatorname{Sex}_{[m]}$ & 0.144 & \pm 0.217 & 36.3 & 0.4 & 0.5129 \\
\hline Body mass & 0.036 & \pm 0.005 & 44.4 & 48.2 & $<0.0001$ \\
\hline Test sequence & -0.053 & \pm 0.078 & 114.3 & 0.5 & 0.4957 \\
\hline Julian day & 0.021 & \pm 0.004 & 71.5 & 30.2 & $<0.0001$ \\
\hline
\end{tabular}

770

771 
772 Table 3 Among-individual correlations $\left(r_{\text {ind }}\right)$ and within-individual correlations $\left(r_{e}\right)$ between

773 docility (time spent immobile during bag test), exploration (distance moved in a 5 min open-

774 field test), sprint speed (fastest speed reached over 1 meter on a given day), and resting

775 metabolic rate (RMR) in 45 Karoo bush rats. All estimates were extracted from a single

776 multivariate mixed model (see Table 1 for sample size and Fig. 2 for variance estimates).

777 Profile likelihoods were used to calculate the 95\% confidence interval (Cl) of $r_{\text {ind }}$ and $r_{e}$

\begin{tabular}{|c|c|c|c|c|c|c|c|}
\hline \multirow[b]{3}{*}{ Trait 1} & \multirow[b]{3}{*}{ Trait 2} & \multicolumn{3}{|c|}{ Among-individual correlations } & \multicolumn{3}{|c|}{ Residual correlations } \\
\hline & & \multirow[b]{2}{*}{$r_{\text {ind }} \pm \mathrm{SE}$} & \multicolumn{2}{|c|}{$95 \% \mathrm{Cl}$} & \multirow[b]{2}{*}{$r_{e} \pm \mathrm{SE}$} & \multicolumn{2}{|c|}{$95 \% \mathrm{Cl}$} \\
\hline & & & lower & upper & & lower & upper \\
\hline Exploration & Docility & $-0.740 \pm 0.216$ & -0.968 & -0.382 & $0.078 \pm 0.104$ & -0.060 & 0.211 \\
\hline Sprint speed & Docility & $0.280 \pm 0.198$ & -0.009 & 0.531 & $0.096 \pm 0.090$ & -0.028 & 0.217 \\
\hline Sprint speed & Exploration & $-0.399 \pm 0.213$ & -0.659 & -0.076 & $-0.151 \pm 0.111$ & -0.296 & 0.002 \\
\hline RMR & Docility & $-0.050 \pm 0.309$ & -0.485 & 0.363 & $0.108 \pm 0.106$ & -0.035 & 0.246 \\
\hline RMR & Exploration & $-0.247 \pm 0.337$ & -0.666 & 0.254 & $-0.085 \pm 0.126$ & -0.250 & 0.087 \\
\hline RMR & Sprint speed & $0.088 \pm 0.263$ & -0.278 & 0.443 & $0.140 \pm 0.111$ & -0.016 & 0.288 \\
\hline
\end{tabular}

779

780

781

782

783

784

785

786

787

788 


\section{Figure captions}

790 Fig. $1 \mathrm{~A}$ ) Body mass (g) and B) sprint speed $\left(\mathrm{cm} \cdot \mathrm{sec}^{-1}\right)$ as function of sex, C) resting metabolic

791 rate $\left(\mathrm{RMR} ; \mathrm{mlO}_{2} \cdot \mathrm{min}^{-1}\right)$ as function of body mass, and $\left.\mathrm{D}\right)$ distance $(\mathrm{m})$ moved during an

792 open-field test and E) sprint speed as function of test sequence in 7 males (blue dots) and 38

793 females (red triangles) Karoo bush rats. Shown are partial residuals (accounting for other

794 effects in the models, see Table 2)

795

796

Fig. 2 Among- and within-individual variation in A) body mass, B) time spent immobile during

797

bag test, C) distance moved in the open-field test, D) sprint speed, and E) resting metabolic

798

rate (RMR) in 7 males (blue dots) and 38 females (red triangles) Karoo bush rats. Shown are

799

residuals from a linear model on the raw scale that included body mass (except in A), sex,

800

test sequence, and Julian day. In each panel, individuals are ordered along the x-axis

801

according to their mean trait values. Among-individual variance $\left(V_{\text {ind }}\right)$, residual variance $\left(V_{e}\right)$,

802

and repeatability $(R)$ estimates with standard errors (SE) were extracted from linear mixed

803

models on $z$-standardised traits ( mean $=0$, total variance $=1$ )

804

805 Fig. 3 Representation of the among-individual correlations $\left(r_{\text {ind }}\right)$ between $(A)$ time spent

806 immobile in the bag test and distance moved in the open field and (B) sprint speed and

807 distance moved in the open field in 7 males (blue dots) and 38 females (red triangles) Karoo

808 bush rats. Displayed are the best linear unbiased predictors (BLUPs \pm SE) extracted from the

809 multivariate model (see Table 3 for correlation estimates) with $z$-standardised traits (mean =

$810 \quad 0$, variance $=1)$

811 
812 Fig. 4 Representation of the among-individual correlations ( $r_{\text {ind }} \pm \mathrm{SE}$, blue dots) and within

813 individual correlations ( $r_{\mathrm{e}} \pm \mathrm{SE}$, red triangles) between distance moved in the open field

814 (Exploration), time spent immobile in the bag test (Docility) and running speeds at each

815 meters during the performance test for 7 male and 38 female Karoo bush rats. Correlation

816 estimates were extracted from the second linear mixed models on z-standardised traits

817 (total variance $=1$ ). Asterisks denote estimates that are significantly different from 0

818

819 

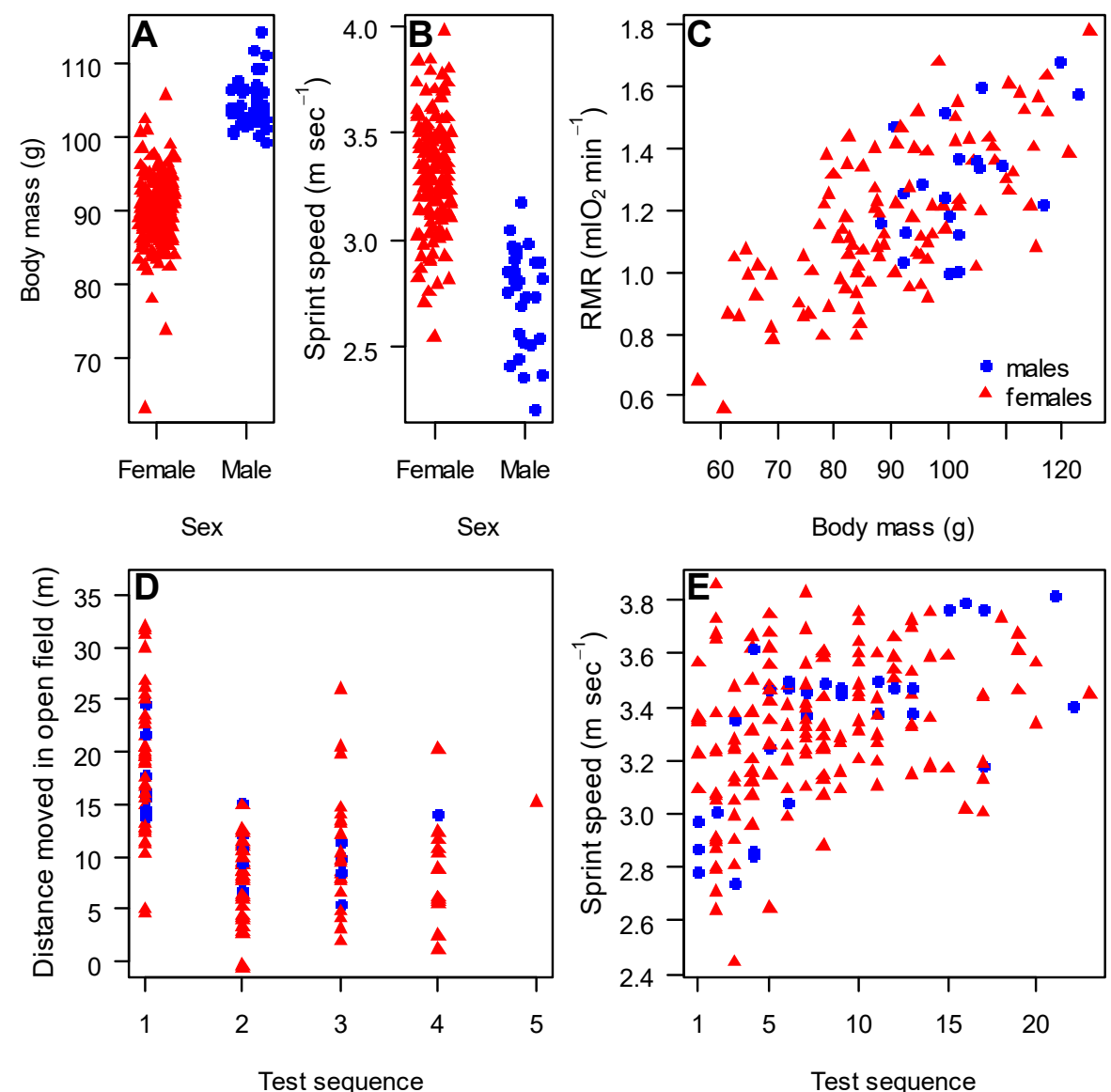

820

Test sequence

Test sequence

$821 \quad$ Fig 1. 

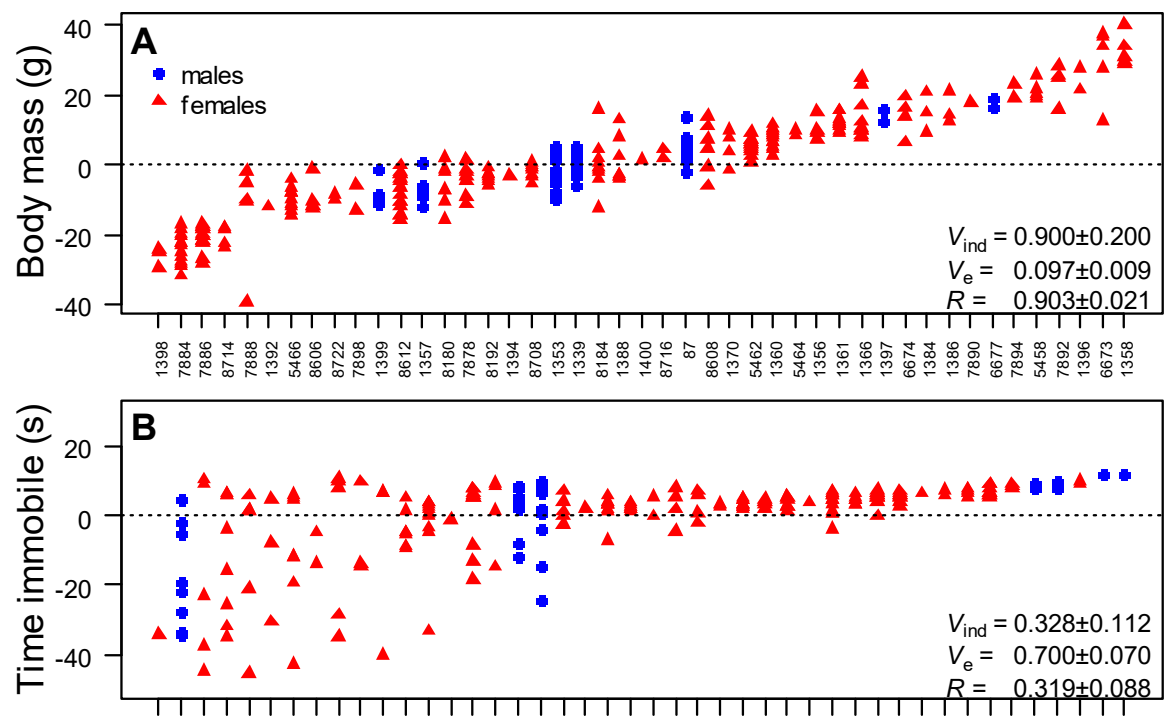

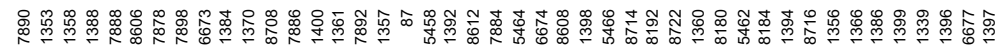
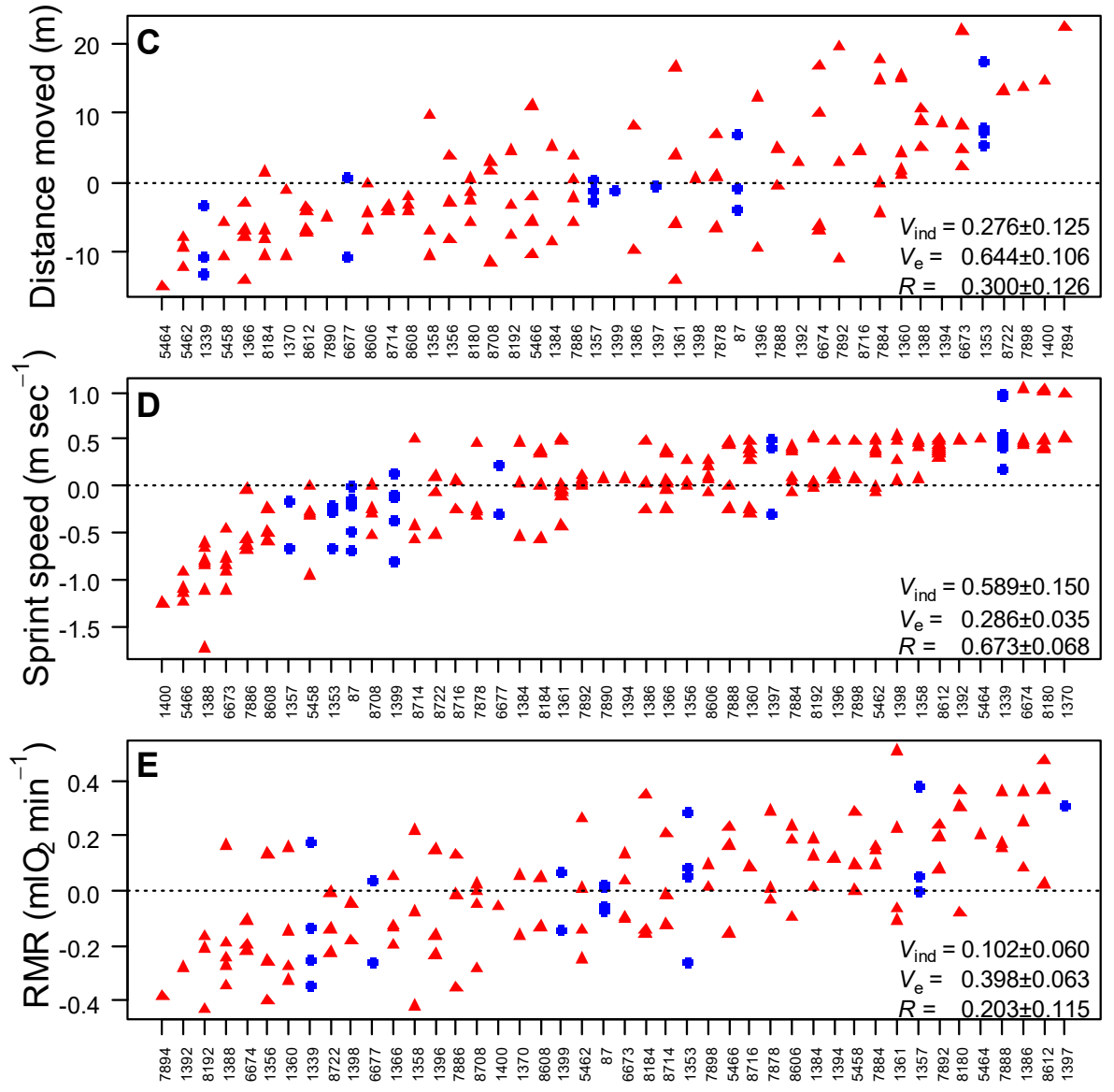

\section{Individuals}

$823 \quad$ Fig. 2 

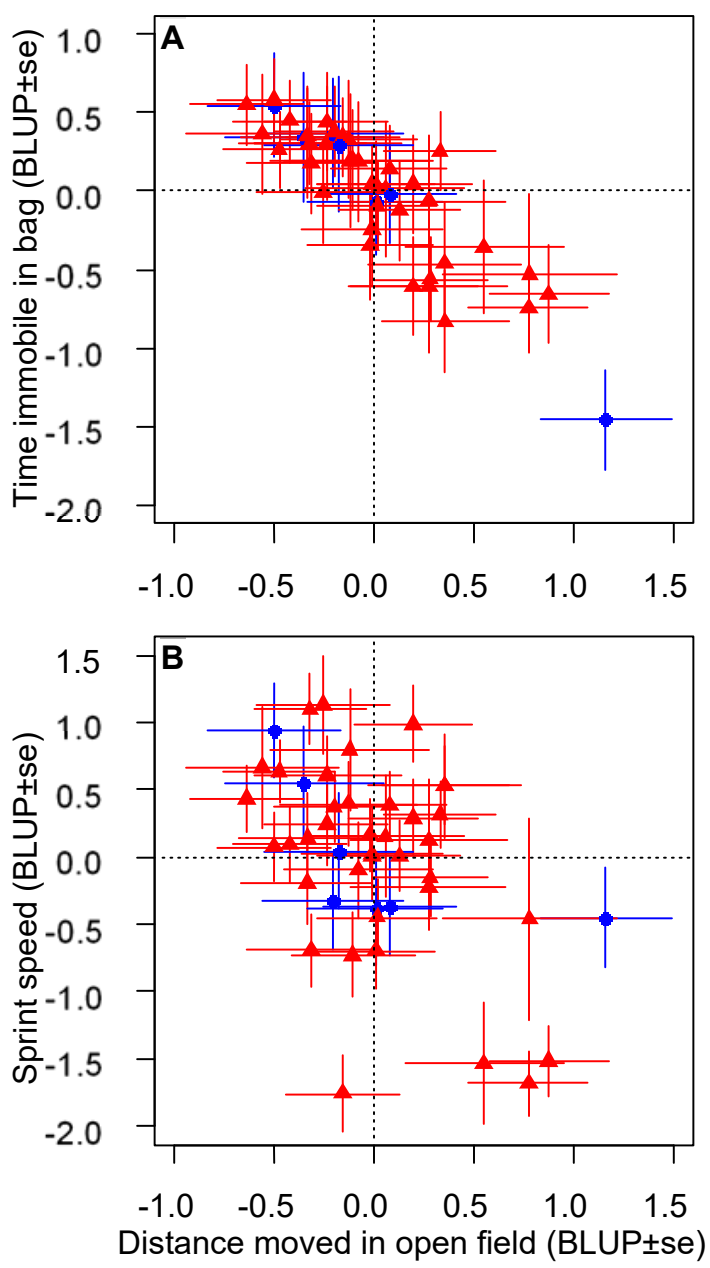

Fig. 3 


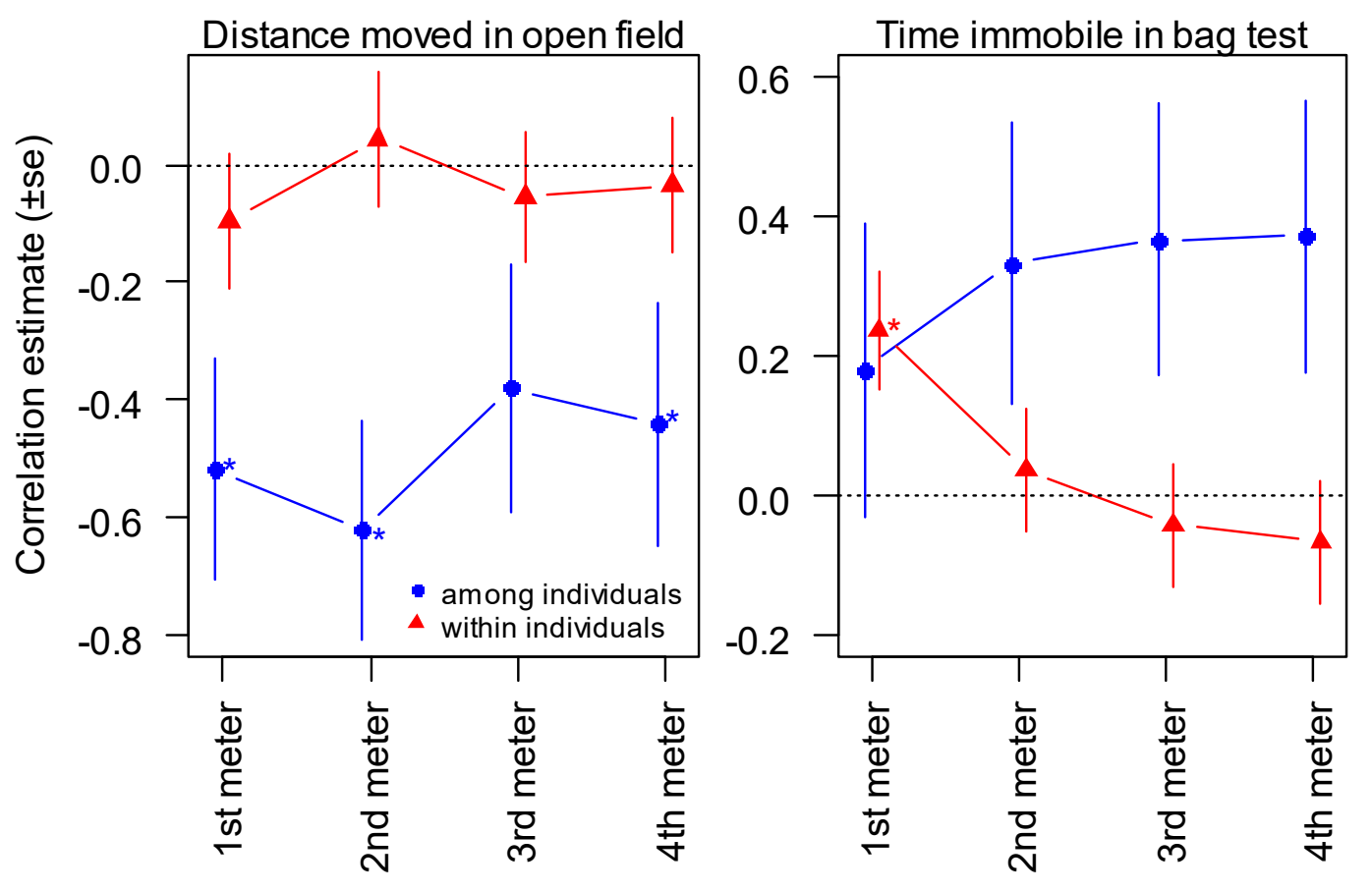

Fig. 4 


\title{
Supplementary material (tables)
}

\author{
The fast and the curious II: \\ performance, personality and metabolism \\ in Karoo bush rats
}

\section{Behavioral Ecology and Sociobiology}

Paul Agnani*, Jennifer Thomson, Carsten Schradin, and Vincent Careau

\author{
*Author for correspondence: \\ pagnani@uottawa.ca \\ ORCID: 0000-0002-1137-0774 \\ Department of Biology \\ University of Ottawa \\ 30 Marie Curie, Ottawa, ON, CANADA, K1N 6N5 \\ Tel: (613) 562-5800 x6349 \\ Fax: (613) 562-5486
}


Table S1 Variance in running speed and metabolic rate across four distinct levels; $V_{\text {ind: }}$ : variance among individuals as estimated by individual identity fitted as random effect, $V_{\text {test }}$ : variance among tests (on separate days) within individuals as estimated by the combination of individual identity and date as a random effect, $v_{\text {trial }}$ : variance among trials within tests as estimated by the combination of individual identity, date, and trial as a random effect, and $V_{e}$ : residual variance among successive measurements within in a given trial (for running speed) or test (for metabolic rate; there is no $V_{\text {trial }}$ component for metabolic rate because only a single trial was conducted per respirometry test).

\begin{tabular}{|c|c|c|c|c|c|c|}
\hline \multirow[b]{2}{*}{ Variance component } & \multicolumn{3}{|c|}{ Running speed } & \multicolumn{3}{|c|}{ Metabolic rate } \\
\hline & estimate & \pm & SE & estimate & \pm & SE \\
\hline$V_{\text {ind }}$ & 0.351 & \pm & 0.098 & 0.325 & \pm & 0.112 \\
\hline$V_{\text {test }}$ & 0.115 & \pm & 0.026 & 0.371 & \pm & 0.073 \\
\hline$V_{\text {trial }}$ & 0.062 & \pm & 0.017 & & & \\
\hline$V_{e}$ & 0.523 & \pm & 0.021 & 0.327 & \pm & 0.024 \\
\hline
\end{tabular}


Table S2 Among-individual correlations $\left(r_{\text {ind }}\right)$ and within-individual correlations $\left(r_{e}\right)$ between docility (time spent immobile during bag test), and exploration (distance moved in a 5 min open-field test) and running speed at each meter during the performance trial (speed-1 = first meter; speed-2 = second meter, speed-3 = third meter, and speed $-4=$ fourth meter) in 45 Karoo bush rats. All estimates were extracted from a single multivariate mixed model.

\begin{tabular}{|c|c|c|c|}
\hline & & Among-individual correlations & Residual correlations \\
\hline Trait 1 & Trait 2 & $r_{\text {ind }} \pm \mathrm{SE}$ & $r_{e} \pm \mathrm{SE}$ \\
\hline Speed-2 & Speed-1 & $0.993 \pm 0.033$ & $0.368 \pm 0.075$ \\
\hline Speed-3 & Speed-1 & $0.897 \pm 0.063$ & $0.230 \pm 0.082$ \\
\hline Speed-4 & Speed-1 & $0.854 \pm 0.080$ & $0.087 \pm 0.086$ \\
\hline Speed-3 & Speed-2 & $0.970 \pm 0.031$ & $0.502 \pm 0.064$ \\
\hline Speed-4 & Speed-2 & $0.970 \pm 0.038$ & $0.375 \pm 0.074$ \\
\hline Speed-4 & Speed-3 & $0.999 \pm N A$ & $0.563 \pm 0.056$ \\
\hline Docility & Speed-1 & $0.180 \pm 0.210$ & $0.236 \pm 0.085$ \\
\hline Docility & Speed-2 & $0.332 \pm 0.202$ & $0.036 \pm 0.088$ \\
\hline Docility & Speed-3 & $0.366 \pm 0.195$ & $-0.042 \pm 0.088$ \\
\hline Docility & Speed-4 & $0.372 \pm 0.195$ & $-0.066 \pm 0.089$ \\
\hline Exploration & Speed-1 & $-0.517 \pm 0.190$ & $-0.096 \pm 0.116$ \\
\hline Exploration & Speed-2 & $-0.622 \pm 0.185$ & $0.044 \pm 0.115$ \\
\hline Exploration & Speed-3 & $-0.380 \pm 0.212$ & $-0.055 \pm 0.111$ \\
\hline Exploration & Speed-4 & $-0.441 \pm 0.208$ & $-0.034 \pm 0.113$ \\
\hline Docility & Exploration & $-0.822 \pm 0.187$ & $0.136 \pm 0.102$ \\
\hline
\end{tabular}


